\title{
The Pain and the Promise of Unfilled Dreams: Infertile Couples
}

\author{
Lynn Clark Callister
}

Susannah loved being married, and she and her husband, Greg, had high hopes for their future together, including the desire to have a large family. She said, "When we made the decision to start trying to get pregnant, my life suddenly became more complicated."

After being diagnosed with polycystic ovarian syndrome, Susannah said, "I was devastated. Although [the doctor] quickly went on to explain options available to help me conceive, I honestly don't remember anything else. Greg and I went home and had to deal with our first major shock. I was really upset. All of my life I had planned on getting married and having children of my own. It never crossed my mind that I might not ever be able to [get pregnant]. I had known couples with infertility problems, but I never imagined it happening to me.

\section{OVERVIEW}

Susannah and Greg are typical of many infertile couples. The infertility experience represents the pain and the promise of often unfulfilled dreams. Infertility is a lonely place for individuals and couples because "infertility is often a silent and solitary crucible, since it is not visible, life-threatening, or disfiguring" (Carroll et al., 2000, p. 286). Infertility is defined as the inability to conceive after 1 year of unprotected intercourse or the inability to carry a pregnancy to a live birth (Leiblum, Aviv, \& Hamer, 1997). Interest in and research devoted to infertility are evidenced by the fact that listings on the Medline database for biomedical research numbered more than 1,166 articles published during 2004 in professional journals alone and in an international survey (Adashi, Cohen, \& Hamberger, 2000).

It is estimated that $10 \%$ to $15 \%$ of couples of childbearing age are infertile, and this number is increasing, especially among younger women (American Society for Reproductive Medicine [ARSM], 1998). Overall, approximately one in four couples will experience infertility, and it is estimated 
Table 6.1 Infertility Risk Factors

\begin{tabular}{ll}
\hline Men & Women \\
Age & Age \\
Exposure to chemicals & Endometriosis \\
Exposure to heat & Heredity \\
Sexually transmitted infections & Polycystic ovary syndrome \\
Smoking & Sexuality \\
Prescription drug use & Sexually transmitted infections \\
Variocele & Smoking \\
Surgery of reproductive organs & Premature menopause \\
Cancer treatment & Surgery of reproductive organs \\
& Cancer
\end{tabular}

SOURCE: Adapted from the American Society of Reproductive Medicine (http://www.asrm.org) and Focus on Fertility (http://www.focusonfertility.org).

that one third of women experience at least one episode of infertility during their reproductive years (Jenkins \& Corrigan, 2004). Female fertility declines with age, which means that with each year there is a possibility of decreased conception (U.S. Department of Health and Human Services, 2004).

Men and women each account for $40 \%$ of infertility, and in $20 \%$ both partners are potentially infertile or the cause of the inability to conceive is unknown. Male and female risk factors for infertility are summarized in Table 6.1 (American Infertility Association, 2004). Infertility affects more than 6.1 million women and their partners in the United States. It is estimated that 7.7 million women will be infertile in the United States by 2025 (ASRM, 2004a). Secondary infertility, or the inability to become pregnant or carry a pregnancy to term after the birth of one or more biological children, is estimated to affect more than 3 million Americans (National Infertility Association, 2004a). Infertility affects those from all socioeconomic levels and racial, ethnic, and cultural groups. It is estimated that $50 \%$ of infertile couples achieve pregnancy within 2 years of infertility treatment.
The cover story of U.S. News and World Report, titled "Miracle Babies: How Science Is Helping Childless Couples Beat the Odds" (Mulrine, 2004), emphasized that childless couples are trying assisted reproductive technology (ART) in record numbers. Rates of success with ART are discouragingly low, with in vitro fertilization having a $26 \%$ success rate per transfer, zygote intrafallopian transfer a $30 \%$ success rate per transfer, and frozen embryo transfer a $16 \%$ success rate (Angard, 1999). National data on the success of ART are available for 384 fertility clinics throughout the United States (Centers for Disease Control and Prevention, 2001). Most health insurance policies do not cover ART, and exorbitant costs are prohibitive and often limit treatment to only those with considerable financial means.

\section{THEORETICAL FRAMEWORK AND ASSUMPTIONS}

The theoretical framework guiding this chapter is Lazarus's model used to explore stress responses and coping mechanisms in infertile couples (Lazarus \& Folkman, 1984). It is 
essential that a biopsychosocial framework guide research and practice because infertility has a profound effect on the biological, psychological, and social aspects of the individual and the family (Engel, 1977, 1980). Three assumptions are associated with this review of infertility. First, it is assumed that becoming a biological parent is a valued and primary role in society. Second, the word couple refers to heterosexual couples living in a committed relationship who may use ART. The third assumption, as articulated by Jordan and Revenson (1999, p. 342), is that "every facet of a couple's psychosocial functioning is affected by the experience of infertility, from shared beliefs about the importance of parenting to the couple's identity to endless discussion of decisions regarding treatment to acceptance of the medical outcome."

\section{CULTURE AND INFERTILITY}

Sociocultural context is an important consideration in the meaning of and responses to infertility. For example, in developing nations such as Nigeria, the major cause of infertility is sexually transmitted infection. Infertile couples often seek treatment from faith healers. Women are often blamed for infertility, and men may divorce their wives or engage in polygyny or both in an effort to have children. Adoption in this culture is generally not socially acceptable, and there are medical, ethical, and legal implications to infertility treatment (Araoye, 2003). In traditional Chinese culture, women are honored for bearing a son, and even in the face of the one-child policy, having a child is extremely important (Chang \& Kuo, 2000; Kartchner \& Callister, 2003; Lee \& Chin, 1996; Lee \& Kuo, 2000). According to a Chinese proverb, "There are three ways one can dishonor one's parents, with childlessness being the foremost" (Lee \& Sun, 2000, p. 153). In Japan, an infertile woman is referred to as an umazume, and in Korea she is referred to as a suknyu, both of which mean a woman made of stone. A Vietnamese woman who is infertile may be designated as gai doc khon con, or the poison woman without children.

Childbearing is one of the most important mitzvahs (mitzvoth) among Orthodox Jews (Callister, Semenic, \& Foster, 1999; Semenic, Callister, \& Feldman, 2004). There are rituals associated with infertility in Jewish couples, including the recitation of the following words associated with ancient scripture (Cardin, 1999):

To everything there is a season: a time to embrace and a time to stand back; a time to sow and a time to reap; a time to laugh and a time to weep; a time to hold on and a time to let go. Our time to sow has ended; our time to let go has begun. (p. 133)

In Mexican society, the infertile woman may be viewed as incomplete, having a curse bestowed for some misdeed. In addition to the use of traditional healers, one coping mechanism is to pray to the virgin of Guadalupe, who is perceived as a survivor of great suffering. Among Native Americans, couples may use traditional healing measures or ceremonies to ensure a pregnancy (St. Hill, Lipson, \& Meleis, 2003).

The importance of fertility among Muslim women is exemplified by the social pressure on newly married women to become pregnant as soon as possible, especially to have sons. Infertile women (aquer) may be stigmatized, divorced, or forced to agree to polygyny. In our study, one Muslim woman said, "Life would be nothing without children" (Khalaf \& Callister, 1997, p. 380), and another Muslim woman explained that "people usually start asking you after the first month of marriage whether you 'save anything inside your abdomen,' meaning 'are you pregnant yet?' So is the nature of life” (p. 380). 


\section{STRESSES OF INFERTILITY}

The stresses of diagnosis and treatment of infertility are multiple and complex, often referred to as a roller coaster of emotions. Both devastating failure and the hope for success are experienced (Bashford, 1999; Hart, 2002), as are often emotionally and physically exhausting experiences (Carroll et al., 2000; Eugster \& Vingerhoets, 1999; Gibson \& Myers, 2000; Lee, Sun, Chao, \& Chen, 2001; Wiczyk, 2000). Carroll et al. note that "couples frequently report high levels of stress, a loss of hope, and feelings of frustration related to the use of complex reproductive technology, the medicalization of intimacy, invasive procedures, surgeries, and potent drugs with problematic side effects”(p. 286).

Triggers for stress and depression include medical appointments that interfere with life schedule, scheduled intercourse instead of spontaneous lovemaking, baby showers or birthday parties for young children, and trying to maintain positive martial relationships while experiencing intensive treatment (American Infertility Association \& Organon Pharmaceuticals, 2004a). Decreased in marital satisfaction and adjustment have been documented (Leiblum et al., 1998). Anger, tension, depression, anxiety, guilt, and frustration are emotions fueled by the infertility experience (Anderson, Sharpe, Rattray, \& Irvine, 2003; Lukse \& Vacc, 1999; Merari, Cherit, \& Modan, 2002).

\section{Gender Differences in Stress and Coping}

The largest body of infertility literature focuses on gender differences in stress levels for the infertile couple. Women may carry the burden because "fertility testing involves more complicated, uncomfortable, and humbling medical procedures for women ... and their treatment is more invasive and more costly than treatment for male infertility.... Her life may be more disrupted than her partner's" (Jordan \& Revenson, 1999, p. 343; Halman, Andrews, \& Abbey, 1993; Phipps, 1993).

In a prospective longitudinal study conducted in the United Kingdom, the emotional distress of infertile couples was measured. Scores on the Hospital Anxiety and Depression Scale did not decrease over time (Anderson et al., 2003). Women had significantly greater infertility-related concerns, such as life satisfaction, sexuality, self-blame, self-esteem, and avoidance of friends, compared to their male partners.

In a study of 120 Taiwanese couples seeking ART, emotional responses to infertility differed according to education levels, duration and number of treatments, and the number of existing children. Women experienced more emotional disturbance associated with infertility than did their partners. In addition, responses had a significantly negative correlation with positive reappraisal. Infertile women adopted more coping behaviors to deal with the challenges of treatment for infertility (Hsu \& Kuo, 2002).

There are also differences in responses depending on the cause of infertility, identified in an East Indian study of 120 infertile couples. Anxiety levels were significantly higher in the partner with the fertility problem. If the male partner was infertile and manifest effects on his personality and social behavior, the woman often became depressed (Dhaliwal, Gupta, Gopalan, \& Kulhara, 2004).

The male infertility experience has been explicated by Petok (2004), who suggests that factors contributing to the gender disparity in response to infertility include men not being reminded on a monthly basis of infertility, the man often being assessed for infertility after the woman, and diagnostic procedures being more complicated and invasive for women. Culturally, media 
images are not as frequent or visible about fathering as they are about mothering, and few men's magazines focus on fathering. In addition, the expectation for men is that they should be strong and emotionally detached. Continuing a genetic line and family name is often extremely important for men.

Although infertility is stressful to both husbands and wives, some researchers have concluded that gender differences in responses to infertility may be striking (Busch, 2001; Gibson \& Myers, 2000; Lee, Sun, \& Chao, 2000; Phipps, 1993). A meta-analysis was done of gender differences in coping with infertility using the Ways of Coping Checklist (Folkman, Lazarus, Dunkel-Schetter, DeLongis, \& Gruen, 1986). Women used three of the eight dimensions significantly more than their male partners: seeking social support, escape avoidance, planful problem solving, and positive reappraisal. These researchers concluded that there may be more similarities than differences in ways of coping between men and women. In a meta-analysis of gender differences associated with the infertility experience, women used social support as a coping strategy more often than men (Jordan \& Revenson, 1999). This is supported by the work of Hsu and Kuo (2002). High levels of agreement between spouses help couples successfully manage the impact of infertility (Hidalgo, Caleffi, Baron, Mattana, \& Chaves, 2004; Peterson, Newton, \& Rosen, 2003).

Susannah described her perceptions of what Greg was experiencing as follows:

I could tell that he was suffering too. I'm not really sure of his emotional experience during this time. I knew that he hurt just as bad as I did, and he cried with me, but he always seemed to be strong for me. Whenever I would try to convey to him my deep worry, he would tell me not to worry and everything would be fine. This answer was helpful for me, but it caused him to bottle up his fears. As time went on, I began to notice a change in him. His drive to succeed, be productive, and to excel all seemed to fade. This only made me even more worried. I didn't know how to help him.

Following infertility treatment, Susannah said,

You can imagine my surprise and great relief when I had a positive pregnancy test. Results in hand, I walked into our apartment and found Greg waiting for me to get home. When I told him, he was so excited. Even now, the image of his face is so vivid. I felt as though a heavy burden had been lifted off of my shoulders. My hope had been renewed and I was very happy.

\section{Losses Experienced by Infertile Couples}

Multiple losses experienced by infertile couples include loss of sexual identity; loss of the childbearing and child-rearing experience and the elusive child they never were able to conceive; loss of the parental identity; loss of close relationships with a spouse, extended family members, and friends; loss of health; loss of status or prestige; loss of a sense of personal control; loss of genetic legacy; loss of a grandparenting relationship; loss of a sense of spirituality and hope for the future; and loss of feelings of self-worth (Carroll et al., 2000, p. 286; Gibson \& Myers, 2000; Gonzales, 2000; Hart, 2002; Imeson \& McMurray, 1996; Johnston, 1994; National Infertility Association, 2004b; Reed, 2001; Sherrod, 2004).

\section{Living With the Responses of Others: Feelings of Alienation}

Often, others, including well-meaning extended family members, may assume that a couple is childless by choice. Comments may include, "So when are you going to start a family? You two aren't getting any 
Table 6.2 Myths About Infertility

Infertility isn't a physical problem. . . . It's all in your head.

Infertility is not very treatable.

Infertility is a female problem.

Exercise more faith in God and you'll get pregnant.

If you can just relax, you can get pregnant.

Adopt a baby and then you'll get pregnant.

Maybe you're doing something wrong.

SOURCE: From Domar and Kelly (2002), Rutter (1996), and Wiczyk (2000).

younger" (National Infertility Association, 2004c). Others may offer "helpful" suggestions for the couple suffering with infertility. Myths associated with infertility often shared with infertile couples by others are shown in Table 6.2 (Domar \& Kelly, 2002; Rutter, 1996; Wiczyk, 2000).

\section{RESPONSES TO \\ INFERTILITY: PHASES OF THE INFERTILITY EXPERIENCE}

Responses to infertility may be categorized into phases, although responses are not orderly or consecutive. The couple may feel emotional highs and lows with hopefulness that a particular ART intervention will help and they will become pregnant, only to face disappointment one more time. In addition, spouses may be in different places emotionally and cognitively, which increases the dissonance between them.

\section{STAGES OF GRIEF IN INFERTILE COUPLES}

Providing personal views of treatment failure, Brown (2002) and Langdrige, Connolly, and Sheeran (2000) remind us that many infertile couples experience multiple failures month after month, treatment after treatment. One woman wrote the following about her experience with infertility: "Childlessness goes on and on. I see no end and I can't come to terms with what may never be. I feel empty, unwhole, angry, fearful, bitter, and lonely" (Kerr, Balen, \& Brown, 1999, p. 935).

Stages of grief may include the following:

Denial: "This can't be happening to me" or "At first I tried to block out all emotion. All I wanted to do was sleep."

Isolation: "We'll keep this to ourselves. No one else can understand our pain."

Anger: Spouses may feel anger toward themselves, as indicated by the response, "If only I had worn better protective equipment when I played sports," because men are more likely to express verbal anger. Anger may be expressed toward the significant other or even other people, including other couples who seem to become pregnant whenever they want. Anger may also be expressed toward the physician and other members of the infertility team, such as, "That stupid doctor doesn't know what he's doing. That's the problem."

Unworthiness: There may be feelings of guilt or unworthiness as individuals blame themselves, such as "I don't know what I've done wrong" or "God must be punishing me for having an abortion when I was sixteen."

Depression: Feelings of a lack of control and a sense of powerlessness may contribute to depression. As one woman expressed, "Feelings of isolation and loneliness flooded over me as I listened to other women talk about their experiences of pregnancy and childbirth. How I wanted to share in their lively conversations. In the past few years I had spent endless days feeling sorry for myself. I had had enough tests, temperature taking, charting, and graphing to last a lifetime" (Zimmerman, 1992, p. 27). There is a need for couples to somehow generate a sense that they are active participants rather than "passive victims of the medical system" (Daniluk, 2001, p. 131). It is helpful for couples to set reasonable limits on the 
pursuit of infertility treatment so that they have a better sense of control in their lives. Developing such limits involves an exploration of their values, needs, and resources (Daniluk, 2001).

Severe grief: "I will never know what it feels like to bear a child." Infertility is a painful emotional experience generating a severe grief response (Barber, 2000; Gonzalez, 2000; Hart, 2002; Juo, Lee, Wang, \& Lee, 1998; Reed, 2001; Rutter, 1996).

Healing grief: "I feel so empty, but the pain is less hurtful now.”

Resolution phase: "Having faith in God's plan for me is probably the only thing that I hang on to" or "It's time to move on." It is challenging to reframe their experience when, despite exhaustive effort, couples remain childless. There may be some residual anger that needs to be resolved (Daniluk, 2001).

Susannah spoke of attending church when another couple with a child sat next to them:

They placed the baby right next to me. At that point the tears started flowing. I eventually had to bury my head in my husband's shoulder and cry. All around me were expectant mothers and little babies. They seemed to jump out at me everywhere I went.

\section{COPING WITH INFERTILITY}

Coping with infertility is often challenging because "infertility can be conceptualized as a chronic, unpredictable, and (personally or medically) uncontrollable stressor that may exceed the couple's coping resources" (Jordan \& Revenson, 1999, p. 345). Carroll et al. (2000) noted the following (see also Johnson, 1996; Kirkman \& Rosenthal, 1999; Lee, Chang, \& Chen, 1997):
Coping strategies include distancing themselves from reminders of infertility (such as avoidance of families with children), instituting measures for regaining control, acting to increase feelings of self-worth in other areas of their lives such as achieving professional success, trying to find meaning in infertility, or sharing the burden with others. (p. 286)

One woman said (Christensen, 1996),

I built an emotional wall around myself, trying to shut out the pain. The wall provided a buffer that protected me for a time, from anyone or anything that reminded me that I had no children. However, the more I closed others out and focused on myself, the more the pain became magnified. It was a sad and lonely life, and as the walls grew higher and thicker, I grew even more discouraged and depressed. (p. 52)

Decision making about ART is anxiety producing. "Couples confronted by infertility are also challenged with sorting through a technically complex and potentially costly decision-making process surrounding possible treatment alternatives" (Carroll et al., 2000, p. 286; Slade, Emery, \& Lieberman, 1997; Thomas \& Rausch, 2002). Couples report that they often have difficulty accessing current information about treatment options and reliable statistics that provide essential information on the probabilities of a successful outcome (Daniluk, 2001).

A study examining the emotional impact of infertility-related stress found that men and women in couples who had equal levels of social infertility stress reported higher levels of marital adjustment compared to those couples experiencing more dissonance. Couples who reported similar needs for parenthood also had significantly higher levels of marital satisfaction. Incongruence in stress and the need to become a parent was significantly associated with depression in women 
but not men (Peterson et al., 2003). Incongruence has also been identified in the desire for twin gestations in individuals who are a part of an infertile couple (Kalra, Milad, Klock, \& Grobman, 2003).

Richly descriptive data were generated from a Canadian qualitative study of infertile couples who had undergone diagnosis and treatment for a mean of 5 years (Daniluk, 2001). The first theme as treatment was initiated was "the beginning: It's only a matter of time." One study participant said,

I'm not a control freak but it's one area of my life that I thought I'd always have control over. You know, I was on the pill for 5 years before we started trying to have a baby ...5 years before we started trying to have a baby . . 5 years when I thought I was in control of my fertility. When I didn't get pregnant it came as quite a shock. (p. 125)

The second theme described being in the middle of infertility treatment, "Work hard enough and you'll get what you want," demonstrated by the following comment (Daniluk, 2001):

They were very optimistic.... The numbers that they quote are often very high so you leave thinking, "Well, I'm gonna be the whatever, the $15 \%$ to $25 \%$ " ... so it's always an upbeat sort of thing and you leave thinking, "Yes, this is gonna work, this is gonna be the month." And it doesn't happen. (p. 125)

The final theme at the culmination of infertility treatment, "When enough is enough," was expressed as follows (Daniluk, 2001):

We used to talk about being like the guinea pig on the wheel in the cage. Once you get on, how do you get off? Every move you make you go faster and the wheel doesn't end. Eventually you have to find a way of just jumping off in midflight to stop it. (p. 128)
Infertile women who become pregnant with the help of ART often have to make heartbreaking decisions about multifetal reduction (MFR). Collopy (2004) identified themes including the presence of infertility as a barrier to contemplating hyperfertility, multiple-birth pregnancy as another form of loss for infertile women, and the lasting effects for having made the decision. These women felt such a sense of irony because they had been desperate to conceive and now were making a decision about destroying a life. They described feelings of desperation that the risks of multiple implantations did not "sink in." A similar study on 11 couples who elected to undergo MFR after infertility treatment found that moral and ethical dilemmas were the most difficult aspect of their experience (Maifield, Hahn, Titler, \& Mullen, 2003).

The circumstance of infertile couples who become pregnant after infertility treatment only to experience fetal loss is particularly poignant and has been documented by Freda and Semelsberger (2003, p. ix) in interviews with women who had this experience. Themes included "back to square one," "a struggle between hope and hopelessness," and "running out of time." One woman said,

We'd been through so much already, so much disappointment, so much crying and pain just to become pregnant. Then the miscarriage. It was the most heart-wrenching experience I've ever been through. But the most frustrating part for me is that we can't be like normal couples who can just go to bed one night and start to conceive another baby. Why them and not us? I might never get pregnant again. (p. ix)

Another woman described her experience of perinatal loss after infertility (National Infertility Association, 2004d):

My dear husband and I have faced reoccurring miscarriages that have been so overwhelming. We have no children and now 
no hopes or dreams. I wish I could have this weight off my shoulder. We feel like we constantly live in rainy days and are just waiting for the sun to shine.

Susannah experienced perinatal loss at 14 weeks and described how she felt when an ultrasound confirmed the loss:

The room was absolutely silent. We were in shock. Minutes before we were going to have a baby. All of a sudden, here we were in a darkened room, not understanding what had just happened or what we should do next. I can't remember ever hurting as bad as I did that day. The pain I felt was so intense that it still brings back very strong emotions when I think about it. Greg and I laid in our bed and cried together. All I could think about was, "Why? Why me? Why us?" I couldn't stop the tears from flowing. Even after I thought surely there couldn't be another tear in my body, there were still many. One minute I felt I must have done something wrong, and the next I just felt like I was broken and unworthy of my husband. Why was it that teenagers and drug addicts are able to get pregnant so easily, but I wasn't? Did I not deserve to be a mother?

\section{SOCIAL SUPPORT AND INFERTILITY}

Social support is one of the most significant variables buffering adjustment to fertility diagnosis, moderating stress (Amir, Horesh, \& Lin-Stein, 1999). Boivin, Scanlan, and Walker (1999) reported that infertile individuals relied on their significant other and extended family members when they were distressed. Other researchers have reported that social support results in greater marital satisfaction and quality, sexual satisfaction, enhanced feelings of self-worth, and psychological well-being. Social support mediates interpersonal conflict, stress, and feelings of loneliness (Abbey, Andrews, \& Halman, 1995; Amir et al., 1999; Boivin et al., 1999; Jirka, Schuett, \& Foxall, 1996). Social support makes a difference for infertile couples, as evidenced by the story of Donna and Joseph, who underwent numerous infertility treatments including surgery and suffered a miscarriage (American Infertility Association \& Organon Pharmaceuticals, 2004b):

Throughout their struggle, Donna and Joseph talked about things openly, allowing friends and family to offer words and prayers of support. "You feel it when everyone really wants it for you and prays for you," Donna said, "It kept us positive that it was going to happen."

Donna did become pregnant and gave birth to a daughter. Sixty people attended a baby shower, a celebration of the couple's 4-year struggle.

An electronic support group for infertile couples is proving to be a helpful coping strategy (Epstein, Rosenberg, Grant, \& Hemenway, 2002). Benefits of participation identified in a survey of 589 participants in Internet support groups sponsored by a nonprofit international infertility organization included education, empowerment, and the diminishment of feelings of depression. This forum can also be inappropriately used for escape avoidance, however. The American Fertility Organization (2004) offers an online discussion group, and quality Web sites that provide information and support for infertile couples are summarized in Table 6.3. For example, one Web site offers an infertility support group, surrogacy support group, and an adoption support group (Society for Assisted Reproductive Technology, 2004). Chat groups are found on the RESOLVE Web site, with topics such as "Survival Strategies: Balancing Infertility, Marriage, and Life," "Unexplained Infertility," and "Shared Risks" (National Infertility 
Table 6.3 Infertility Web Sites

\begin{tabular}{ll}
\hline Web Site & Organization \\
http://www.advancedfertility.com & Advanced Fertility Center of Chicago \\
http://www.theafa.org & American Fertility Association \\
http://www.asrm.com & American Society for Reproductive Medicine \\
http://www.focusonfertility.org & Focus on Fertility \\
http://www.inciid.org & International Council on Infertility Information Dissemination \\
http://www.child.org.uk & National Infertility Support Network (CHILD) \\
http://www.fertilityplus.org & Fertility Plus \\
http://www.resolve.org & RESOLVE: National Infertility Association \\
http://www.sart.org & Society for Assisted Reproductive Technology \\
http://www.4woman.gov & U.S. Department of Health and Human Services Office on \\
& Women's Health \\
\hline
\end{tabular}

Table 6.4 Breaking the Cycle of Stress

Find a support group.

Seek professional emotional help, including couples therapy.

Investigate complementary therapies.

Pamper yourself.

Keep a journal.

Take a "vacation" from treatment.

Reconnect with your partner.

Maintain healthy habits, including diet and exercise.

SOURCE: Adapted from the American Fertility Association (2004), the American Society of Reproductive Medicine (http://www.asrm.org), Bashford (1999), Focus on Fertility (http://www.focusonfertility.org), Hsu and Kuo (2002), Johnson (1996), Lukse and Vacc (1999); and Sherrod (2004).

Association, 2004e). It should be noted that only $2 \%$ of 197 infertility-related Web sites met the standards for quality and accountability (Okamura, Bernstein, \& Fidler, 2002).

Infertile couples who wanted to adopt a child but instead enrolled in a program preparing them to be foster parents were found to differ in their responses to the program from couples with children. Infertile couples had feelings of a deep emotional loss resulting from their inability to have a child (Bevc, Jerman, Ovsenik, \& Ovsenik, 2003). Suggested coping strategies on the
American Fertility Association and the Focus on Fertility Web sites are summarized in Table 6.4.

\section{IMPLICATIONS FOR CLINICAL PRACTICE}

The importance of psychosocial support and interventions by health care providers for infertile couples cannot be overemphasized. It should be implemented in conjunction with ART counseling. As expressed by Stotland (2002), infertility and ART involve 
Table 6.5 Signs Indicating Counseling Is Needed

Persistent feelings of sadness, guilt, or worthlessness

Social isolation

Loss of interest in usual activities and relationships

Depression

Agitation and anxiety

Increased mood swings

Constant preoccupation with infertility

Marital discord

Difficulty concentrating and remembering

Increased use of alcohol and drugs

Change in appetite, weight, or sleep patterns

Thoughts about suicide or death

Difficulty with scheduled intercourse

SOURCE: Adapted from the American Society for Reproductive Medicine (http://www.asrm.org).

the most intimate body parts and the most poignant hopes and profound disappointments. Issues include reactions to the infertility diagnosis, gender differences in stress and coping, and parenting following successful ART (Schmidt, Holstein, Boivin, Sangren, et al., 2003; Schmidt, Holstein, Boivin, Tjorhnhoj-Thomsen, et al., 2003).

Brucker and McKenry (2004) examined the relationship between support from health care providers (HCPs) and psychological adjustment in 120 men and women experiencing infertility. For women, perceived support from HCPs did not predict levels of stress, depression, or anxiety. For men, greater levels of perceived support from HCPs predicted lower levels of stress and anxiety. HCPs have the opportunity to provide needed support not only to assist in conception but also to assist in better psychological adjustment to the infertility diagnosis. Signs that suggest the need for professional counseling for those who are infertile are summarized in Table 6.5 (American Society for Reproductive Medicine, 2004b).

Savitz-Smith (2003) summarized the literature on counseling infertile couples. Types of counseling include implications, support, and therapeutic. Implications counseling explores with people how any proposed treatment would affect them, their family, and any child born as a result of treatment. Support counseling provides emotional support at any time before, during, or after treatment. Therapeutic counseling focuses on the effects, consequences, and resolution of treatment and infertility (Bagshawe \& Taylor, 2003). Sherrod (2004) identified the recommendations for clinical practice with infertile couples listed in Table 6.6. Providing opportunities for couples to share their perceptions and reflect on the meaning of their experiences is essential (Daniluk, 2001).

\section{RESEARCH RECOMMENDATIONS}

Studies with larger sample sizes should be performed. Prospective longitudinal studies that differentiate those with different infertility diagnoses would be appropriate. Research on study participants who have received extensive infertility treatment and those who have discontinued treatment is recommended. More data are needed on the infertility experience in different cultural and 
Table 6.6 Counseling Infertile Couples

Awareness/advice: Do not speak inappropriately or uninformed about infertility. Do not perpetuate false hopes. Present a realistic picture of treatment options and their success rates. Do not offer advice unless it is asked for. A listening ear may be the most effective intervention. Remember that adoption is expensive, complicated, and lengthy and may not meet the needs of an individual or couple to have a biological child.

Blame/balance: Remember that infertility affects couples, not just individuals. The causes of infertility are varied, but in a majority of cases a couple has done nothing "wrong." Help couples financially by being accurate in all charges for various procedures and providing information on insurance coverage and other potential ways that treatment may be paid for. Help couples establish a balance regarding each partner's limits in the process of trying to conceive (Hart, 2002). Do not assume that the male partner does not care. Although there are gender differences in emotional responses, both partners "feel" the experience (Busch, 2001; Gibson \& Myers, 2000; Hart, 2002).

Competence/compassion: Remember that procedures are painful. Respond with sensitivity. Welcome and encourage the woman's partner who can offer support during procedures. Reduce the couple's anxiety and pain as you prepare for procedures. Refer the couple to local support groups, such as RESOLVE (Bashford, 1999). Help couples find ways to relieve their stress, including taking a break from infertility treatment (Sherrod, 2004).

ethnic groups. Research on those who are voluntarily childless and have had either a vasectomy or tubal ligation but now desire to have a child is important. Issues related to couples who experiencing secondary infertility after successfully bearing children are another potential area of research that should be explored. Outcomes evaluation of psychosocial interventions with infertile couples is recommended.

Reflecting on her experiences with infertility, the perinatal loss of three unborn children, and the removal of a ruptured fallopian tube because of a tubal pregnancy, Susannah said,

My only hope comes from knowing that I still have the ability to perhaps have a baby. It is not guaranteed, and I have been trying to prepare myself for the possibility that it may never happen in this life. I think I am still in the stage where I believe we will be counted in the group of couples who are able to conceive with treatment. It is too painful to think about the other outcome.

\section{REFERENCES}

Abbey, A., Andrews, F. M., \& Halman, L. J. (1995). Provision and receipt of social support and disregard: What is their impact on the marital life quality of infertile and fertile couples? Journal of Personality and Social Psychology, 68(3), 455-469.

Adashi, E. Y., Cohen, J., \& Hamberger, L. (2000). Public perception on infertility and its treatment: An international survey. Human Reproduction, 15, 330-334.

American Fertility Association. (2004). Considering treatment: Infertility risk assessment. Retrieved February 15, 2005, from http://www.americaninfertility.org

American Infertility Association \& Organon Pharmaceuticals. (2004a). Breaking the cycle of stress and sadness. Retrieved October 23, 2004, from http://www .focusonfertility.org/cope_sadstress.htm 
American Infertility Association \& Organon Pharmaceuticals. (2004b). Real life stories: Dreams do come true. Retrieved October 23, 2004, from http://www .focusonfertility.org/cope_reallifestory.htm

American Society for Reproductive Medicine. (1998). Fact sheet: In vitro fertilization. Birmingham, AL: Author.

American Society for Reproductive Medicine. (2004a). Fertility and sterility. Retrieved February 15, 2005, from http://asrm.org

American Society for Reproductive Medicine. (2004b). Infertility: An overview. Retrieved February 15, 2005, from http://asrm.org

Amir, M., Horesh, N., \& Lin-Stein, T. (1999). Infertility and adjustment in women: The effects of attachment style and social support. Journal of Clinical Psychology in Medical Settings, 6(4), 463-479.

Anderson, K. M., Sharpe, M., Rattray, A., \& Irvine, D. S. (2003). Distress and concerns in couples referred to a specialist infertility clinic. Journal of Psychosomatic Research, 54(4), 353-355.

Angard, N. T. (1999). Diagnosis infertility: Karen and Matthew. Association of Women's Health, Obstetric, and Neonatal Nursing Lifelines, 3(3), 22-29.

Araoye, M. O. (2003). Epidemiology of infertility: Social problems of the infertile couples. Western African Journal of Medicine, 22(2), 190-196.

Bagshawe, A., \& Taylor, A. (2003). ABC's of subfertility counseling. British Medical Journal, 327, 1038-1040.

Barber, D. (2000). A fertile field. Nursing Standard, 14(26), 77-78.

Bashford, R. A. (1999). Psychological aspects of infertility. Clinical Nurse Specialist Spectrum, 4(4), 62-72.

Bevc, V., Jerman, J., Ovsenik, R., \& Ovsenik, M. (2003). Experiencing infertilitySocial work dilemmas in child adoption procedures. Collegium Antropologicum, 27(2), 445-460.

Boivin, J., Scanlan, L. C., \& Walker, S. M. (1999). Why are infertile patients not using psychosocial counseling? Human Reproduction, 14(5), 1384-1391.

Brown, C. J. (2002). Managing treatment failures: A patient's view. Human Fertility: Journal of the British Fertility Society, 5(4), 199-202.

Brucker, P. S., \& McKenry, P. C. (2004). Support from health care providers and the psychological adjustment of individuals experiencing infertility. Journal of Obstetric, Gynecologic, and Neonatal Nursing, 33(5), 597-603.

Busch, S. (2001). Chasing a miracle: Why infertile women continue to stay in treatment. Association of Black Nursing Faculty Journal, 12, 116-123.

Callister, L. C., Semenic, S., \& Foster, J. C. (1999). Cultural and spiritual meanings of childbirth: Orthodox Jewish and Mormon women. Journal of Holistic Nursing, 17(3), 280-295.

Cardin, N. B. (1999). Tears of sorrow, seeds of hope. Woodstock, VT: Jewish Lights.

Carroll, J. S., Robinson, W. D., Marshall, E. S., Callister, L. C., Olsen, S. F., Dyches, T. T., et al. (2000). The family crucibles of illness, disability, death, and other losses. In D. C. Dollahite (Ed.), Strengthening our families (pp. 278-292). Salt Lake City, UT: Bookcraft.

Centers for Disease Control and Prevention. (2001). Assisted reproductive technology success rates: 2001. Retrieved October 23, 2004, from http://www.cdc .gov/reproductivehealth/ART01/nation.htm

Chang, S. Y., \& Kuo, B. J. (2000). Psychosocial responses among couples undergoing first time and repeat cycles of IVF-ET treatment. Nursing Research (Taiwan), 8, 190-201. 
Christensen, J. M. (1996). I yearned for a baby. Ensign, 27(8), 52-53.

Collopy, K. S. (2004). "I couldn't think that far": Infertile women's decision making about multifetal reduction. Research in Nursing and Health, 27, 75-86.

Daniluk, J. C. (2001). "If we had it to do over again. . . " Couples' reflections on their experiences of infertility treatments. Family Journal: Counseling and Therapy for Couples and Families, 9(2), 122-133.

Dhaliwal, L. K., Gupta, K. R., Gopalan, S., \& Kulhara, P. (2004). Psychological aspects of infertility due to various causes-A prospective study. International Journal of Fertility and Women's Medicine, 49(1), 44-48.

Domar, A. D., \& Kelly, A. L. (2002). Conquering infertility. New York: Penguin.

Engel, G .L. (1977). The need for a new medical model: A challenge for biomedicine. Science, 196, 129-136.

Engel, G. L. (1980). The clinical application of the biopsychosocial model. American Journal of Psychiatry, 137(5), 535-544.

Epstein, Y. M., Rosenberg, H. S., Grant, T. V., \& Hemenway, B. A. N. (2002). Use of the Internet as the only outlet for talking about infertility. Fertility and Sterility, 78(3), 507-514.

Eugster, A., \& Vingerhoets, A. J. J. (1999). Psychological aspects of in-vitro fertilization: A review. Social Science and Medicine, 48, 575-589.

Folkman, S., Lazarus, R. S., Dunkel-Schetter, C., DeLongis, A., \& Gruen, R. (1986). The dynamics of a stressful encounter: Cognitive appraisal, coping, and encounter outcomes. Journal of Personality Sociology and Psychology, 50, 992-1003.

Freda, M. C., \& Semelsberger, C. F. (2003). Miscarriage after infertility. Minneapolis, MN: Fairview Press.

Gibson, D. M., \& Myers, J. E. (2000). Gender and infertility: A relational approach to counseling women. Journal of Counseling and Development, 4, 400-410.

Gonzales, L. O. (2000). Infertility as a transformational process: A framework for psychotherapeutic support of infertile women. Issues in Mental Health Nursing, 21, 619-633.

Halman, L. J., Andrews, F. M., \& Abbey, A. (1993). Gender differences and perceptions about childbearing among infertile couples. Journal of Obstetric, Gynecologic, and Neonatal Nursing, 23(7), 593-600.

Hart, V. A. (2002). Infertility and the role of psychotherapy. Issues in Mental Health Nursing, 23(11), 31-41.

Hidalgo, M. P., Caleffi, L., Baron, A., Mattana, E., \& Chaves, M. L. (2004). Cohesion and adaptability among individuals under treatment for infertility. Psychological Reports, 94(1), 55-65.

Hsu, Y., \& Kuo, B. (2002). Evaluations of emotional reactions and coping behaviors as well as correlated factors for infertile couples receiving assisted reproductive technologies. Journal of Nursing Research, 10(4), 291-302.

Imeson, M., \& McMurray, A. (1996). Couple's experiences of infertility: A phenomenological study. Journal of Advanced Nursing, 24, 1014-1022.

Jenkins, J., \& Corrigan, L. (2004). Current thinking on management of infertility. Clinical Pulse, 5, 20-23.

Jirka, J., Schuett, S., \& Foxall, M. J. (1996). Loneliness and social support in infertile couples. Journal of Obstetric, Gynecologic, and Neonatal Nursing, 25(1), 55-60.

Johnson, C. L. (1996). Regaining self-esteem: Strategies and interventions for the infertile woman. Journal of Obstetric, Gynecologic, and Neonatal Nursing, 25, 291-295. 
Johnston, G. P. (1994). The wish, the wait, the wonder. New York: HarperCollins. Jordan, C., \& Revenson, T. A. (1999). Gender differences in coping with infertility: A meta-analysis. Journal of Behavioral Medicine, 22(4), 341-358.

Juo, B. J., Lee, S. H., Wang, Y. M., \& Lee, M. S. (1998). Association of traditional attitudes toward childbirth and grief responses among infertile couples. Chung Shan Medical Journal, 9, 89-99.

Kalra, S. K., Milad, M. P., Klock, S. C., \& Grobman, M. A. (2003). Infertility patients and their partners: Differences in the desire for twin gestation. Obstetrics and Gynecology, 102, 152-155.

Kartchner, R., \& Callister, L. C. (2003). Giving birth: Voices of Chinese women. Journal of Holistic Nursing, 21(2), 100-116.

Kerr, J., Balen, A., \& Brown, C. (1999). The experiences of couples in the United Kingdom who have had infertility treatment. Human Reproduction, 14, 934-938.

Khalaf, I., \& Callister, L. C. (1997). Cultural meanings of childbirth: Muslim women living in Jordan. Holistic Nursing, 15(4), 373-388.

Kirkman, M., \& Rosenthal, D. (1999). Representations of reproductive technology in women's narratives of infertility. Women and Health, 29(2), 17-36.

Langdrige, D., Connolly, K., \& Sheeran, P. (2000). Reasons for wanting a child: A network analytic study. Journal of Reproductive and Infant Psychology, 18(4), 321-338.

Lazarus, R. S., \& Folkman, S. (1984). Stress, coping and appraisal. New York: Springer.

Lee, S. H., \& Kuo, B. J. (2000). Chinese traditional childbearing attitudes and infertile couples in Taiwan. Image: The Journal of Nursing Scholarship, 32, 54.

Lee, T. Y., Chang, S. P., \& Chen, C. C. (1997). The comparison of distress, stress, and coping strategies on infertile couples. Nursing Research (Taiwan), 5(5), 425-438.

Lee, T. Y., \& Chin, G. C. (1996). The perceived stressors for infertile women in one medical center in southern Taiwan. Nursing Research (Taiwan), 4(2), 186-193.

Lee, T .Y., \& Sun, G. H. (2000). Psychosocial response of Chinese infertile husbands and wives. Archives of Andrology, 45(3), 149-154.

Lee, T. Y., Sun, G. H., \& Chao, S. C. (2000). The effect of an infertility diagnosis on the distress, marital and sexual satisfaction between husbands and wives. Human Reproduction, 16(8), 1762-1767.

Lee, T. Y., Sun, G. H., Chao, S. C., \& Chen, C. C. (2001). Development of the coping scale for infertile couples. Archives of Andrology, 45(3), 149-154.

Leiblum, S. R., Aviv, A., \& Hamer, R. (1997). Life after infertility treatment: A long term investigation of marital and sexual function. Human Reproduction, 13(12), 3569-3574.

Lukse, M. P., \& Vacc, N. A. (1999). Grief, depression, and coping in women undergoing infertility treatment. Obstetrics and Gynecology, 9(2), 245-251.

Maifield, M., Hahn, S., Titler, M. G., \& Mullen, M. (2003). Decision making regarding multifetal reduction. Journal of Obstetric, Gynecologic, and Neonatal Nursing, 32(3), 357-369.

Merari, D., Cherit, A., \& Modan, B. (2002). Emotional reactions and attitudes prior to in vitro fertilization: An interspouse study. Psychology and Health, 17(5), 629-640.

Mulrine, A. (2004, September 27). Miracle babies: How science is helping childless couples beat the odds. U.S. News and World Report, 60-67. 
National Infertility Association. (2004a). Secondary infertility. Retrieved February 15, 2005, from http://www.resolve.org/main/national/treatment/diagnosis/2nd infertility.jsp

National Infertility Association. (2004b). Hidden no more: The hidden aspects of infertility. Retrieved February 15, 2005, from http://www.resolve.org/main/ national/trying/whatis/hidden.jsp

National Infertility Association. (2004c). Managing family and friends. Retrieved February 15, 2005, from http://www.resolve.org/main/national/coping/talk/ family/family.jsp

National Infertility Association. (2004d). Retrieved February 15, 2005, from http:// www.resolve.org

National Infertility Association. (2004e). Retrieved October 23, 2004, from http:// www.resolve.org

Okamura, K., Bernstein, J., \& Fidler, A. T. (2002). Assessing the quality of infertility resources on the World Wide Web: Tools to guide clients through the maze of fact and fiction. Journal of Midwifery and Women's Health, 47(4), 264-268.

Peterson, B. D., Newton, C. R., \& Rosen, K. H. (2003). Examining congruence between partners' perceived infertility-related stress and its relationship to marital adjustment. Family Process, 42(1), 59-70.

Petok, W. D. (2004). Male infertility: Family building magazine. Retrieved October 23, 2004, from http://www.resolve.org

Phipps, S. A. (1993). A phenomenological study of couples' infertility: Gender influence. Holistic Nurse Practitioner, 7(2), 44-56.

Reed, S. A. (2001). Medical and psychological aspects of infertility and assisted reproductive technology for primary health care providers. Military Medicine, 166, 1018-1026.

Resolve: The National Infertility Association. (2004). Infertility myths and facts. Retrieved October 23, 2004, from http://www.resolve.org/main/national/ coping/demystify/mythfact.jsp

Rutter, M. (1996, Spring). Families without children. This People, 38, 41, 43, 45-46, $49,51$.

Savitz-Smith, J. (2003). Couples undergoing infertility treatment: Implications for counselors. Family Journal, 11(4), 383-387.

Schmidt, L., Holstein, B. E., Boivin, J., Sangren, H., Tjornhoj-Thomsen, T., Blaabjerg, J., Hald, F., et al. (2003b). Patients' attitudes to medical and psychosocial aspects of care in fertility clinics. Human Reproduction, 18(3), 628-637.

Schmidt, L., Holstein, B. E., Boivin, J., Tjorhnhoj-Thomsen, T., Balaabjerg, J., Hald, F., et al. (2003a). High ratings of satisfaction with infertility treatment are common: Findings from the Copenhagen Multi-Centre Psychosocial Infertility Research Programme. Human Reproduction, 18(12), 2638-2646.

Semenic, S., Callister, L .C., \& Feldman, P. (2004). Giving birth: The voices of Orthodox Jewish women living in Canada. Journal of Obstetric, Gynecologic, and Neonatal Nursing, 33(1), 80-87.

Sherrod, R. A. (2004). Understanding the emotional aspects of infertility. Journal of Psychosocial Nursing, 42(3), 40-47.

Slade, P., Emery, J., \& Lieberman, B. A. (1997). A prospective longitudinal study of emotions and relationships in in-vitro fertilization treatment. Human Reproduction, 12, 183-190. 


\section{FAMILY AND HEALTH ISSUES}

Society for Assisted Reproductive Technology. (2004). ASRM patient fact sheet. Retrieved February 15, 2005, from http://www.sart.org

St. Hill, P., Lipson, J. G., \& Meleis, A. I. (2003). Caring for women cross-culturally. Philadelphia: F. A. Davis.

Stotland, N. L. (2002). Psychiatric issues related to infertility, reproductive technologies, and abortions. Primary Care: Clinics in Office Practice, 29(1), 13-26.

Thomas, V., \& Rausch, D. T. (2002). Evaluating psychosocial factors and psychological reactions to infertility treatment. Journal of Couple Relationship Therapy, 1(2), 33-49.

U.S. Department of Health and Human Services (2004). Fertility awareness and infertility. Retrieved February 15, 2005, from http://www.4woman.gov

Wiczyk, H. (2000). Infertility: A modern workup. Female Patients, 25(8), 72-78.

Zimmerman, S. (1992). Would I ever be a mother? Ensign, 23, 27-28. 